\title{
Preferences for Health Information Technologies Among US Adults: Analysis of the Health Information National Trends Survey
}

Onur Asan ${ }^{1}$, PhD; Farion Cooper $\mathrm{II}^{2}$, BA; Sneha Nagavally ${ }^{2}$, MS; Rebekah J Walker ${ }^{2}$, PhD; Joni S Williams ${ }^{2}$, MD, MPH; Mukoso N Ozieh ${ }^{2}$, MD, MSc; Leonard E Egede ${ }^{2}$, MD, MS

${ }^{1}$ School of Systems and Enterprises, Stevens Institute of Technology, Hoboken, NJ, United States
${ }^{2}$ Center for Advancing Population Science (CAPS), Medical College of Wisconsin, Milwaukee, WI, United States

Corresponding Author:

Onur Asan, PhD

School of Systems and Enterprises

Stevens Institute of Technology

1 Castle Point Terrace

Hoboken, NJ, 07030

United States

Phone: 12012165514

Email: oasan@ stevens.edu

\section{Abstract}

Background: Emerging health technologies are increasingly being used in health care for communication, data collection, patient monitoring, education, and facilitating adherence to chronic disease management. However, there is a lack of studies on differences in the preference for using information exchange technologies between patients with chronic and nonchronic diseases and factors affecting these differences.

Objective: The purpose of this paper is to understand the preferences and use of information technology for information exchange among a nationally representative sample of adults with and without 3 chronic disease conditions (ie, cardiovascular disease [CVD], diabetes, and hypertension) and to assess whether these preferences differ according to varying demographic variables.

Methods: We utilized data from the 2012 and 2014 iteration of the Health Information National Trends Survey (N=7307). We used multiple logistic regressions, adjusting for relevant demographic covariates, to identify the independent factors associated with lower odds of using health information technology (HIT), thus, identifying targets for awareness. Analyses were weighted for the US population and adjusted for the sociodemographic variables of age, gender, race, and US census region.

Results: Of 7307 participants, 3529 reported CVD, diabetes, or hypertension. In the unadjusted models, individuals with diabetes, CVD, or hypertension were more likely to report using email to exchange medical information with their provider and less likely to not use any of the technology in health information exchange, as well as more likely to say it was not important for them to access personal medical information electronically. In the unadjusted model, additional significant odds ratio (OR) values were observed. However, after adjustment, most relationships regarding the use and interest in exchanging information with the provider were no longer significant. In the adjusted model, individuals with CVD, diabetes, or hypertension were more likely to access Web-based personal health information through a website or app. Furthermore, we assessed adjusted ORs for demographic variables. Those aged $>65$ years and Hispanic people were more likely to report no use of email to exchange medical information with their provider. Minorities (Hispanic, non-Hispanic black, and Asian people) were less likely to indicate they had no interest in exchanging general health tips with a provider electronically.

Conclusions: The analysis did not show any significant association among those with comorbidities and their proclivity toward health information, possibly implying that HIT-related interventions, particularly design of information technologies, should focus more on demographic factors, including race, age, and region, than on comorbidities or chronic disease status to increase the likelihood of use. Future research is needed to understand and explore more patient-friendly use and design of information technologies, which can be utilized by diverse age, race, and education or health literacy groups efficiently to further bridge the patient-provider communication gap.

(J Med Internet Res 2018;20(10):e277) doi: 10.2196/jmir.9436 


\section{KEYWORDS}

chronic conditions; eHealth; health information exchange; health information technology; internet; mHealth; mobile phone

\section{Introduction}

The burden of chronic diseases continues to grow, and they remain the most common cause of death and disability worldwide [1]. More than half of the adults in the United States have at least one chronic condition (eg, hypertension, coronary heart disease, stroke, diabetes, and cancer) [2,3]. Cardiovascular disease (CVD) and diabetes are two common chronic conditions that share common risk factors including age, genetic factors, obesity, poor nutrition, impaired glucose tolerance, and physical inactivity [4]. Moreover, diabetes is a well-known risk factor for CVD as it can increase atherosclerosis and cause elevated blood pressure and cholesterol levels in many individuals [4]. In addition, hypertension is a well-established risk factor for CVD, and studies have shown a relationship between hypertension and both vascular and structural cardiac remodeling [5]. Furthermore, inflammatory mediators such as damage-associated molecular patterns have been associated with CVD, hypertension, and diabetes [6]. Immune-mediated and adaptive immune responses have been implicated in hypertension and other vascular diseases as well [7]. Death from CVD rose by $>40 \%$ between 1990 and 2013 as a result of factors such as population increase, aging, and epidemiological changes in chronic diseases [8]. Thus, it is critical for the population with chronic diseases to maintain effective disease management to achieve an improved quality of life and health outcomes $[9,10]$.

The need for continuous monitoring, long-term planning, and frequent interaction of patients with chronic diseases with their providers might be addressed with ongoing technological advancements [1]. Emerging health technologies such as remote patient monitoring systems, mobile phone intervention programs, electronic health databases, smartphone apps, instant messaging, video calling, and patient portals are increasingly being used in health care for communication, data collection, patient monitoring, education, and facilitating adherence to chronic disease management [11-28]. It has been suggested that these technologies can assist in reducing both the burden and cost of CVD around the world [29-31].

Specifically, the use of Web-based and mobile health (mHealth) intervention programs has led to a few suggestions for the technological intervention to improve health information exchange (HIE). In fact, it has been shown that information exchange via various portals and mobile intervention has led to an increased adherence to healthy lifestyle programs, treatment regimens, and disease prevention programs [11-13,15,32]. However, the literature on this topic is very general and seldom concentrates on different chronic diseases and conditions. Literature that does converge on specific diseases like diabetes and chronic kidney disease only concentrate on one type of electronic health (eHealth) technology at a time $[32,33]$. The evidence that concentrates on the broad use of technology in addressing CVD specifically is limited [34]. There is also a lack of studies on differences in the preference for using information exchange technologies between patients with chronic and nonchronic diseases and factors affecting these differences. From a design and intervention development perspective, it would be critical to understand user differences and their relationship with demographic factors to augment the uptake of the newly developed information technologies.

The purpose of this paper is to understand the preferences and use of technology for information exchange among a nationally representative sample of adults with and without 3 chronic disease conditions (ie, CVD, diabetes, and hypertension) and to assess whether these preferences differ according to varying demographic variables.

\section{Methods}

\section{Sample Population}

Data for this study were derived from the Health Information National Trends Survey (HINTS). HINTS is a large-scale, household interview survey of US noninstitutionalized adults aged $\geq 18$ years. HINTS gathers information from the general population to investigate trends in the utilization of health communication systems between providers and patients, specifically pertaining to access and usage [35]. We utilized data from HINTS 4 Cycles 2 (2012) and 4 (2014), which were obtained using the single mode mailing service and the Next Birthday Method for respondent selection. To perform a consistent selection of respondents across all households, we used the Next Birthday Method; in this technique, adults who have a next birthday coming up are requested to finish the survey for every family unit.

The sampling frame came from a collection of databases used by the Marketing Systems Group to obtain a random sample of addresses. This was then grouped into 3 specific sampling strata: (1) high concentrations of minority populations; (2) low concentrations of minority populations; and (3) counties in Central Appalachia (regardless of minority populations) [35]. A total of 12,055 households received the 4-part mailed questionnaire in Cycle 2, and 13,996 households received the 4-part mailed questionnaires in Cycle 4. The response rate was $39.97 \%(4818 / 12,055)$ for Cycle 2 and $34.44 \%(4820 / 13,996)$ for Cycle 4 [36,37]. Additional information about data collection and methodologies can be found in the corresponding methodology reports for HINTS 4 Cycles 2 and 4. The sampling methodology allowed for weighting of the sample to provide population estimates [36,37]. Further details on survey design and sampling strategies of the overall HINTS mechanism were published in a previous work [38].

We identified individuals with CVD, diabetes, or hypertension through self-reported diagnosis via the questions "Has a doctor or other health professional ever told you that you have diabetes or high blood sugar," "Has a doctor or other health professional ever told you that you have high blood pressure or hypertension?" and "Has a doctor or other health professional ever told you that you have a heart condition such as heart 
attack, angina, or congestive heart failure?" Individuals included in the sample population answered yes to any of the diagnoses. "Missing data" or "Inapplicable" response type for these three questions was considered to be a missing value for having a chronic condition. These 2 versions of HINTS resulted in a sample of 7307 total individuals who answered relevant questions and for whom demographic data were collected, and this was the sample size used for this analysis [36,37].

\section{Measures}

The main outcome variables were questions asking about exchanging information with providers and accessing medical records. The questions that were included in the analysis and the responses dichotomized have been detailed in Multimedia Appendix 1.

We modeled negative responses using multiple logistic regressions adjusting for relevant covariates to identify independent factors associated with lowers odds of using health information technology (HIT) and, therefore, identify targets for awareness. Analyses were weighted for the US population and adjusted for the sociodemographic variables of age, gender, race, and US census region. Covariates were categorized as age (18-34 years, 35-44 years, 45-64 years, and 65-110 years); gender (female, male); race (Hispanic, non-Hispanic white, non-Hispanic black or African American, non-Hispanic Asian, and non-Hispanic other [non-Hispanic American Indian or Alaska Native or non-Hispanic, Native Hawaiian or other Pacific Islander or non-Hispanic multiple races mentioned]); and region (Northeast, Midwest, South, and West).

\section{Statistical Analysis}

First, basic demographic statistics were conducted using demographic attributes: age ("18-34," "35-44," "45-64," " $\geq 65$ " years), gender ("Male," "Female"), race ("Hispanic," "non-Hispanic white," "non-Hispanic black or African American," "non-Hispanic Asian," "non-Hispanic other"), and census region ("Northeast," "Midwest," "South," "West"). We calculated weighted population frequencies and percentiles. Second, we analyzed each question with an unadjusted logistic regression model, followed by an adjusted logistic regression model. To model for dichotomous outcome variables, we used logit model. In a logit model, log odds of a dependent variable are modeled as a linear combination of independent variables. To implement the logit model, we used generalized linear model function and linked the binomial family to logistic regression to develop a logistic model for the analyses. Models were adjusted for age, race, gender, and region. All analyses were conducted using $\mathrm{R}$ statistical tool, with a $P<.05$ considered statistically significant. To analyze the weighted sample, we implemented the R Survey package with type "JKn" to include the weight samples across the dataset. Furthermore, we used sample weights from the survey data to analyze weighted population estimates and replicate weights to compute SE of estimates using the jackknife replication method.

\section{Results}

In all, 7307 participants (weighted population of 230,993,888) answered the questions used in this analysis. Within this sample,
3529 participants (weighted population of 90,748,995) reported CVD, diabetes, or hypertension. In addition, 3.33\% (243/7307) of observations were with missing data. Table 1 shows the demographics of the population. Of those with CVD, diabetes, or hypertension, $42.35 \%$ (1482/3529) were aged 45-64 years and $31.06 \%$ (1094/3529) were aged $\geq 65$ years. Furthermore, non-Hispanic white people represented $60.79 \%$ (2142/3529) of the population, and the Southern region of the United States represented $39.25 \%(1383 / 3529)$ of the population.

Table 2 displays the unadjusted and adjusted odds ratios (ORs) for HIT use and interest in exchanging information with a provider. In the unadjusted models, individuals with diabetes, CVD, or hypertension were more likely to report using email to exchange medical information with their provider (OR 1.431; 95\% CI 1.113-1.838) and less likely to not use any of the technology in HIE (OR 0.778; 95\% CI 0.618-0.979). Additionally, those with diabetes, CVD, or hypertension were less likely to report that health apps never led to asking new questions of their provider (OR 0.526; 95\% CI 0.331-0.838) and were also more likely to report having no interest in exchanging electronic appointment reminders (OR 1.818; $95 \%$ CI 1.388-2.380), in exchanging general health tips with health care provider electronically (OR 1.283; 95\% CI 1.004-1.639), in exchanging medication reminders with health care provider electronically (OR 1.440; 95\% CI 1.135-1.827), in exchanging diagnostic information with health care provider electronically (OR 1.269; 95\% CI 1.011-1.592), or in exchanging symptoms with health care provider electronically (OR 1.263; 95\% CI 1.004-1.588). However, after adjustment, all relationships regarding the use of and interest in exchanging information with the provider were no longer significant.

Table 3 displays the unadjusted and adjusted ORs for interest in accessing personal medical information. In the unadjusted models, individuals with CVD, diabetes, or hypertension were more likely to say that it was not important for them to access personal medical information electronically (OR 1.496; 95\% CI 1.142-1.959); however, in the adjusted models, these individuals were more likely to access Web-based personal health information through a website or app (OR 1.877; 95\% CI 1.210-2.912).

Because a number of relationships lost significance after adjustment for demographic covariates, Multimedia Appendix 2 displays the adjusted ORs for demographic variables included in models presented in Tables 2 and 3 that showed significant unadjusted differences by chronic disease diagnosis to determine which demographic variables explained the relationship. Models in Multimedia Appendix 2 were adjusted by demographic covariates age, gender, race or ethnicity, and census region and the primary variable (presence of diabetes, CVD, or hypertension). Individuals aged $>65$ years (OR 2.32; 95\% CI 1.55-3.49) and Hispanic people (OR 1.95; 95\% CI 1.26-3.01) were more likely to report no use of email to exchange medical information with their provider. Conversely, non-Hispanic black people were less likely to report that they never used an app that led to questions for their provider (OR 0.32; 95\% CI 0.16-0.63), whereas individuals living in the Western region of the country were more likely to report never using an app that led to questions or a second opinion (OR 2.18; 95\% CI 
1.08-4.41). Minorities were less likely to indicate that they had no interest in exchanging general health tips with a provider electronically (Hispanic people [OR 0.55; 95\% CI 0.34-0.88], non-Hispanic black people [OR 0.36; 95\% CI 0.23-0.56], and Asian people [OR 0.33 ; 95\% CI 0.16-0.70]). In addition, non-Hispanic black people were less likely to report having no interest in exchanging medication reminders with providers (OR 0.62; 95\% CI 0.41-0.95). Individuals aged 45-64 and >65 years were more likely to report no interest in exchanging a variety of medical information with their providers and more likely to say that it was not important to access their own information electronically. However, individuals aged $>65$ years were less likely to say that they never accessed personal medical information electronically in the past 12 months (OR 0.25; $95 \%$ CI 0.13-0.47). Finally, women were more likely to report no interest in exchanging diagnostic information with their provider (OR 1.32; 95\% CI 1.03-1.71).

Table 1. Weighted population demographic characteristics: sample $n=7307$, weighted population $\mathrm{N}=230,993,888$.

\begin{tabular}{|c|c|c|c|}
\hline \multirow[t]{2}{*}{ Demographics } & \multicolumn{2}{|l|}{ Weighted population, $\mathrm{n}(\%)$} & \multirow[t]{2}{*}{$P$ value } \\
\hline & $\begin{array}{l}\text { Population with diabetes, } \mathrm{CVD}^{\mathrm{a}} \text {, } \\
\text { or hypertension }(\mathrm{n}=3529)\end{array}$ & $\begin{array}{l}\text { Population without diabetes, CVD, } \\
\text { or hypertension }(n=3535)\end{array}$ & \\
\hline Gender & & & .59 \\
\hline Male & $1683(47.76)$ & $1672(47.34)$ & \\
\hline Female & $1845(50.19)$ & $1863(51.53)$ & \\
\hline Age (years) & & & $<.001^{\mathrm{b}}$ \\
\hline $18-34$ & $351(9.83)$ & $1512(42.80)$ & \\
\hline $35-44$ & $458(13.19)$ & $671(19.02)$ & \\
\hline $45-64$ & $1482(42.35)$ & $996(28.19)$ & \\
\hline$>65$ & $1094(31.06)$ & $267(7.63)$ & \\
\hline Race & & & .12 \\
\hline Hispanic & $413(11.74)$ & $530(14.98)$ & \\
\hline Non-Hispanic white & $2142(60.79)$ & $2177(61.63)$ & \\
\hline Non-Hispanic black or African American & 399 (11.35) & $335(9.48)$ & \\
\hline Non-Hispanic Asian & $92(2.61)$ & $198(5.62)$ & \\
\hline Non-Hispanic other & $81(2.34)$ & $70(1.96)$ & \\
\hline Region & & & .22 \\
\hline Northeast & $620(17.58)$ & $664(18.86)$ & \\
\hline Midwest & $780(22.16)$ & $752(21.28)$ & \\
\hline South & $1383(39.25)$ & $1260(35.65)$ & \\
\hline West & $741(21.00)$ & $856(24.22)$ & \\
\hline
\end{tabular}

${ }^{\mathrm{a}} \mathrm{CVD}$ : cardiovascular disease.

${ }^{\mathrm{b}}$ Statistically significant relationships at $P<.05$, with the presence of diabetes, cardiovascular disease, or hypertension being the primary indicator. 
Table 2. Unadjusted and adjusted odds ratios (ORs) for the use of and interest in exchanging information with a provider among individuals with the presence of a chronic condition.

\begin{tabular}{lll}
\hline Odds $^{\mathrm{a}}$ & Unadjusted OR (95\% CI) & Adjusted OR (95\% CI) \\
\hline
\end{tabular}

Odds of reporting use

In the past 12 months, used any of following to exchange info with health care professional?

$\begin{array}{ll}\text { Email } & 1.431(1.113-1.838)^{\mathrm{b}} \\ \text { Short message service text message } & 1.039(0.688-1.571) \\ \text { App } & 0.983(0.602-1.604) \\ \text { Video } & 1.922(0.560-6.599) \\ \text { Social media } & 0.936(0.499-1.756) \\ \text { Fax } & 0.874(0.553-1.379) \\ \text { None } & 0.778(0.618-0.979)^{\mathrm{b}}\end{array}$

$1.128(0.865-1.470)$

$0.955(0.594-1.536)$

$0.734(0.426-1.262)$

$1.379(0.310-6.134)$

$0.659(0.325-1.337)$

$0.811(0.503-1.308)$

$0.963(0.753-1.233)$

Odds of responding "no" or "never"

Have apps on smartphone or tablet related to health led to asking doctor new questions $\quad 0.526(0.331-0.838)^{\mathrm{b}}$ or getting second opinion from another doctor?

How interested in exchanging appointment reminders with health care provider electron- $1.818(1.388-2.380)^{\mathrm{b}}$ ically?

How interested in exchanging general health tips with health care provider electronically? $1.283(1.004-1.639)^{\mathrm{b}}$

How interested in exchanging medication reminders with health care provider electron- $1.440(1.135-1.827)^{\mathrm{b}}$ ically?

How interested in exchanging lab or test results with health care provider electronically? 1.215 (0.951-1.552)

$0.938(0.683-1.289)$

How interested in exchanging diagnostic information with health care provider electron- $1.269(1.011-1.592)^{\mathrm{b}}$

$0.996(0.757-1.312)$ ically?

How interested in exchanging vital signs with health care provider electronically?

$1.259(0.986-1.607)$

$1.022(0.754-1.386)$

How interested in exchanging lifestyle behaviors with health care provider electronically? 1.187 (0.942-1.496)

$0.882(0.669-1.163)$

How interested in exchanging symptoms with health care provider electronically? $\quad 1.263(1.004-1.588)^{\mathrm{b}}$

$0.832(0.621-1.116)$

${ }^{\mathrm{a}}$ The model was adjusted by demographic covariates: age, gender, race or ethnicity, and census region.

${ }^{\mathrm{b}}$ Statistically significant relationships at $P<.05$, with the presence of diabetes, cardiovascular disease, or hypertension being the primary indicator.

Table 3. Unadjusted and adjusted odds ratios (ORs) for use of and interest in accessing personal medical information among individuals with the presence of a chronic condition.

$\begin{array}{llll}\text { Odds }^{\mathrm{a}} & \text { Unadjusted OR (95\% CI) } & \text { Adjusted OR (95\% CI) }\end{array}$

Odds of responding not important or not confident or no or more times

How important is it for doctors to share your medical information with each other $\quad 0.960(0.680-1.355)$

$1.282(0.790-2.080)$ electronically?

How important would it be for you to access personal medical information electronically?

$1.496(1.142-1.959)^{\mathrm{b}}$

$1.089(0.761-1.557)$

How confident are you that safeguards are present to protect your medical records $\quad 0.817(0.638-1.048)$

$0.902(0.670-1.213)$

from being seen by people who are not permitted to view them?

Have you been offered access to personal health info through a website or app by your $1.043(0.837-1.301)$

health care provider?

$1.041(0.817-1.324)$

\section{Odds of increasing number of times}

In the past 12 months, how many times did you access personal health information $\quad 1.251(0.824-1.898)$ through a website or app?

${ }^{a}$ The model was adjusted by demographic covariates: age, gender, race or ethnicity, and census region.

${ }^{\mathrm{b}}$ Statistically significant relationships at $P<.05$, with the presence of diabetes, cardiovascular disease, or hypertension being the primary indicator. 


\section{Discussion}

\section{Principal Findings}

In this study, we examined and compared patients' attitudes toward the use of health information technologies for HIE between providers and patients with and without the chronic (diabetes, CVD, or hypertension) conditions. The analyses showed that while unadjusted differences existed in responses to the use of HIT based on the existence of chronic disease, the inclusion of the demographic factors of gender, race, age, and region of residence removed this statistical significance and may explain the differences. This suggests that demographic differences are more important than differences due to presence or absence of a chronic disease. This is particularly important as interventions are developed to increase the use of HIT across different population groups in the United States. Specifically, our findings suggest that future interventions should target the unique needs of the elderly and ethnic minorities regardless of their disease status.

Our findings show that older individuals, regardless of the presence of a chronic condition, indicated less interest in using HIT to communicate or exchange information with their provider. Previous studies have also reported similar findings. One study showed the rate of HIT use among those aged $\geq 65$ years to be less than that among younger patients [39]. Another study also showed that older adults were less likely than younger adults to value the importance of Patient Health Records [33]. There might be several reasons behind these findings, and they include the following: (1) greater ease of use and comfort with technology among younger adults [40]; (2) poor usability, availability, and accessibility of HIT functions tailored to the elderly [41-43]; (3) lower health literacy in the elderly [44,45]; (4) lower educational attainment and income in the elderly $[3,46]$; and (5) unique challenges from having chronic diseases that are more prevalent in the elderly and that impede the use of technology (eg, arthritis, vision impairment) [47]. However, the potential of technology for better communication and disease management is clear [48]; therefore, given the burden of chronic disease in the elderly, it is imperative to develop more user-friendly interfaces to facilitate better use of HIT for this age group. In addition, the results showed that adults aged 65 years with chronic disease reported no interest in exchanging medical information through the Web with their doctors, although they stated that they accessed health info electronically in the past 12 months. This might show that this group would like to access information on the Web to get informed, but still prefer other type of communication channels to discuss with their providers, such as in person or via phone over electronic information exchange. Finally, a recent study has shown increased use of mHealth technologies by the elderly group [49]; likewise, this study also signals that if these technologies are designed to be more patient friendly and if they address cognitive load as well as understand the needs of elderly patients, we would witness increased use and more eHealth information exchange among this group too.

In addition, we found that minorities showed more interest in using HIT, particularly for general health tips and medication reminders. In addition, non-Hispanic black people were less likely to report that they never used an app that led to questions for their provider. Some previous studies have shown that minorities are less likely to seek out Web-based health information [48], but our results show that this trend may be changing given the advancement in technology and rate of possession of mobile phones among minority populations. A recent Pew Internet \& American Life Project's 2013 Health Online study has also shown that minorities (Hispanic and non-Hispanic black people) reported using their mobile phones to access health information, especially information related to pregnancy and weight, more than non-Hispanic white people [50,51]. It is also interesting to see that given the increased use of smartphone among minorities to access health information through app or Web, they are not more likely to report or exchange information with their providers. This changing trend suggests that future interventions for ethnic minorities should take greater advantage of technology, especially eHealth and mobile technology, which can also address and solve some disparity problems in the long run.

Some past studies have shown mixed results on gender differences in the eHealth use and perception of HIE [52-54]. In our study, the only question indicating a difference by gender suggests that men may be more interested in using HIT to discuss diagnostic information with their providers. Finally, individuals with chronic conditions were more likely to access Web-based personal health information through a website or app for the last 12 months. One reason for this finding might be that individuals with no chronic condition did not need or have any issue requiring them to access their health records compared with individuals with chronic conditions.

\section{Limitations}

In this analysis, we used a large, population-based sample providing generalizable results and investigated a variety of HIT options; however, there are some limitations worth noting. First, the data were cross-sectional and, therefore, cannot offer information on causality. Second, the response rate for HINTS was $21 \%-35 \%$, and therefore, it may have more selection bias than other national surveys. Local or regional studies that provide more detailed data with a higher response rate should be conducted to validate these findings. Finally, there are several possible confounders that may further explain the relationships noted that were not included in the dataset.

\section{Conclusions}

This study compares the HIT use for information exchange by individuals with and without chronic conditions (diabetes, CVD, or hypertension) and potential factors that influence HIT use. The findings did not show any significant association among those with comorbidities and their proclivity toward health information. This study suggests that HIT-related interventions, particularly the design of mHealth technologies, should focus more on demographic factors, including race, age, and region, than on chronic disease status or comorbidities to increase the likelihood of use. Future research is needed to understand and explore more patient-friendly use and design of mHealth apps, which can be utilized by various age, race, and education or health literacy groups efficiently to further bridge the 
communication gap between patients and their provider. A more qualitative exploration would be beneficial to identify why

certain groups do and do not use HIT for HIE purposes.

\section{Acknowledgments}

This study was supported by the National Institute of Diabetes and Digestive and Kidney Diseases (Grant K24DK093699; Principal Investigator: LEE, MD, MS). This award was also funded by the Research and Education Program Fund, which is a component of the Advancing a Healthier Wisconsin endowment at the Medical College of Wisconsin (Principal Investigator: OA, PhD).

\section{Authors' Contributions}

OA, JSW, RJW, and LEE designed the study. SN acquired and analyzed the data. SN, RJW, and LEE developed the analyses, and OA, JSW, SN, RJW, MNO, and LEE interpreted the data. OA, JSW, RJW, MNO, and LEE critically revised the manuscript for important intellectual content.

\section{Conflicts of Interest}

None declared.

\section{Multimedia Appendix 1}

Survey questions used in the analysis.

[PDF File (Adobe PDF File), 64KB-Multimedia Appendix 1]

\section{Multimedia Appendix 2}

Adjusted odds ratios for selected questions with demographics information.

[PDF File (Adobe PDF File), 46KB-Multimedia Appendix 2]

\section{References}

1. Hamine S, Gerth-Guyette E, Faulx D, Green BB, Ginsburg AS. Impact of mHealth chronic disease management on treatment adherence and patient outcomes: a systematic review. J Med Internet Res 2015;17(2):e52 [FREE Full text] [doi:

10.2196/jmir.3951] [Medline: 25803266]

2. Kruse CS, Argueta DA, Lopez L, Nair A. Patient and provider attitudes toward the use of patient portals for the management of chronic disease: a systematic review. J Med Internet Res 2015;17(2):e40 [FREE Full text] [doi: 10.2196/jmir.3703] [Medline: 25707035]

3. Zhang Y, Lauche R, Sibbritt D, Olaniran B, Cook R, Adams J. Comparison of Health Information Technology Use Between American Adults With and Without Chronic Health Conditions: Findings From The National Health Interview Survey 2012. J Med Internet Res 2017 Oct 05;19(10):e335 [FREE Full text] [doi: 10.2196/jmir.6989] [Medline: 28982644]

4. Tong B, Stevenson C. Comorbidity of cardiovascular disease, diabetes and chronic kidney disease in Australia. Cardiovascular Disease Series 2007;28:37 [ [FREE Full text]

5. Koene RJ, Prizment AE, Blaes A, Konety SH. Shared Risk Factors in Cardiovascular Disease and Cancer. Circulation 2016 Mar 15;133(11):1104-1114 [FREE Full text] [doi: 10.1161/CIRCULATIONAHA.115.020406] [Medline: 26976915]

6. De Miguel C, Rudemiller NP, Abais JM, Mattson DL. Inflammation and hypertension: new understandings and potential therapeutic targets. Curr Hypertens Rep 2015 Jan;17(1):507 [FREE Full text] [doi: 10.1007/s11906-014-0507-z] [Medline: 25432899]

7. Harrison D, Guzik T, Lob H. Inflammation, immunity, and hypertension. Hypertension 2011;57(2):132-140 [FREE Full text]

8. Roth GA, Forouzanfar MH, Moran AE, Barber R, Nguyen G, Feigin VL, et al. Demographic and epidemiologic drivers of global cardiovascular mortality. N Engl J Med 2015 Apr 02;372(14):1333-1341 [FREE Full text] [doi: 10.1056/NEJMoa1406656] [Medline: 25830423]

9. Duff OM, Walsh DM, Furlong BA, O'Connor NE, Moran KA, Woods CB. Behavior Change Techniques in Physical Activity eHealth Interventions for People With Cardiovascular Disease: Systematic Review. J Med Internet Res 2017 Aug 02;19(8):e281 [FREE Full text] [doi: 10.2196/jmir.7782] [Medline: 28768610]

10. Whitehead L, Seaton P. The Effectiveness of Self-Management Mobile Phone and Tablet Apps in Long-term Condition Management: A Systematic Review. J Med Internet Res 2016;18(5):e97 [FREE Full text] [doi: 10.2196/jmir.4883] [Medline: 27185295]

11. PausJenssen AM, Spooner BA, Wilson MP, Wilson TW. Cardiovascular risk reduction via telehealth: a feasibility study. Can J Cardiol 2008 Jan;24(1):57-60 [FREE Full text] [Medline: 18209771] 
12. Purcell R, McInnes S, Halcomb EJ. Telemonitoring can assist in managing cardiovascular disease in primary care: a systematic review of systematic reviews. BMC Fam Pract 2014 Mar 07;15:43 [FREE Full text] [doi: 10.1186/1471-2296-15-43] [Medline: 24606887]

13. Brewer LC, Kaihoi B, Zarling KK, Squires RW, Thomas R, Kopecky S. The use of virtual world-based cardiac rehabilitation to encourage healthy lifestyle choices among cardiac patients: intervention development and pilot study protocol. JMIR Res Protoc 2015;4(2):e39 [FREE Full text] [doi: 10.2196/resprot.4285] [Medline: 25857331]

14. Posadzki P, Mastellos N, Ryan R, Gunn LH, Felix LM, Pappas Y, et al. Automated telephone communication systems for preventive healthcare and management of long-term conditions. Cochrane Database Syst Rev 2016 Dec 14;12:CD009921 [FREE Full text] [doi: 10.1002/14651858.CD009921.pub2] [Medline: 27960229]

15. Coughlin SS, Prochaska JJ, Williams LB, Besenyi GM, Heboyan V, Goggans DS, et al. Patient web portals, disease management, and primary prevention. Risk Manag Healthc Policy 2017;10:33-40 [FREE Full text] [doi:

10.2147/RMHP.S130431] [Medline: 28435342]

16. Shaw RJ, Ferranti J. Patient-provider internet portals—patient outcomes and use. Comput Inform Nurs 2011 Dec;29(12):714-8; quiz 719. [doi: 10.1097/NCN.0b013e318224b597] [Medline: 21697705]

17. Hallberg I, Taft C, Ranerup A, Bengtsson U, Hoffmann M, Höfer S, et al. Phases in development of an interactive mobile phone-based system to support self-management of hypertension. Integr Blood Press Control 2014;7:19-28 [FREE Full text] [doi: 10.2147/IBPC.S59030] [Medline: 24910510]

18. Free C, Phillips G, Felix L, Galli L, Patel V, Edwards P. The effectiveness of M-health technologies for improving health and health services: a systematic review protocol. BMC Res Notes 2010;3:250 [FREE Full text] [doi: 10.1186/1756-0500-3-250] [Medline: 20925916]

19. Artinian NT. Telehealth as a tool for enhancing care for patients with cardiovascular disease. J Cardiovasc Nurs 2007;22(1):25-31. [Medline: 17224694]

20. Schwartz KA, Britton B. Use of telehealth to improve chronic disease management. N C Med J 2011;72(3):216-218. [Medline: 21901920]

21. Inglis SC, Clark RA, McAlister FA, Ball J, Lewinter C, Cullington D, et al. Structured telephone support or telemonitoring programmes for patients with chronic heart failure. Cochrane Database Syst Rev 2010(8):CD007228. [doi: 10.1002/14651858.CD007228.pub2] [Medline: 20687083]

22. Dale LP, Whittaker R, Eyles H, Mhurchu CN, Ball K, Smith N, et al. Cardiovascular Disease Self-Management: Pilot Testing of an mHealth Healthy Eating Program. J Pers Med 2014;4(1):88-101 [FREE Full text] [doi: 10.3390/jpm4010088] [Medline: 25562145]

23. Otte-Trojel T, de Bont A, van de Klundert J, Rundall TG. Characteristics of patient portals developed in the context of health information exchanges: early policy effects of incentives in the meaningful use program in the United States. J Med Internet Res 2014;16(11):e258 [FREE Full text] [doi: 10.2196/jmir.3698] [Medline: 25447837]

24. Chow CK, Islam SMS, Farmer A, Bobrow K, Maddision R, Whittaker R, et al. Text2PreventCVD: protocol for a systematic review and individual participant data meta-analysis of text message-based interventions for the prevention of cardiovascular diseases. BMJ Open 2016 Oct 17;6(10):e012723 [FREE Full text] [doi: 10.1136/bmjopen-2016-012723] [Medline: 27798018]

25. Thakkar J, Karthikeyan G, Purohit G, Thakkar S, Sharma J, Verma S, et al. Development of macaronic Hindi-English 'Hinglish' text message content for a coronary heart disease secondary prevention programme. Heart Asia 2016;8(2):32-38 [FREE Full text] [doi: 10.1136/heartasia-2016-010789] [Medline: 27752288]

26. Rawstorn JC, Gant N, Meads A, Warren I, Maddison R. Remotely Delivered Exercise-Based Cardiac Rehabilitation: Design and Content Development of a Novel mHealth Platform. JMIR Mhealth Uhealth 2016;4(2):e57 [FREE Full text] [doi: 10.2196/mhealth.5501] [Medline: 27342791]

27. Park LG, Beatty A, Stafford Z, Whooley MA. Mobile Phone Interventions for the Secondary Prevention of Cardiovascular Disease. Prog Cardiovasc Dis 2016;58(6):639-650. [doi: 10.1016/j.pcad.2016.03.002] [Medline: 27001245]

28. Bashshur RL, Shannon GW, Smith BR, Alverson DC, Antoniotti N, Barsan WG, et al. The empirical foundations of telemedicine interventions for chronic disease management. Telemed J E Health 2014 Sep;20(9):769-800 [FREE Full text] [doi: 10.1089/tmj.2014.9981] [Medline: 24968105]

29. Ammenwerth E, Schnell-Inderst P, Hoerbst A. The impact of electronic patient portals on patient care: a systematic review of controlled trials. J Med Internet Res 2012;14(6):e162 [FREE Full text] [doi: 10.2196/jmir.2238] [Medline: 23183044]

30. Martínez A, Everss E, Rojo-Alvarez JL, Figal DP, García-Alberola A. A systematic review of the literature on home monitoring for patients with heart failure. J Telemed Telecare 2006;12(5):234-241. [doi: 10.1258/135763306777889109] [Medline: 16848935$]$

31. Seto E. Cost comparison between telemonitoring and usual care of heart failure: a systematic review. Telemed J E Health 2008 Sep;14(7):679-686. [doi: 10.1089/tmj.2007.0114] [Medline: 18817497]

32. Lee M, Lee K, Yoo S, Park C. Impact of initial active engagement in self-monitoring with a telemonitoring device on glycemic control among patients with type 2 diabetes. Sci Rep 2017 Jun 20;7(1):3866 [FREE Full text] [doi: 10.1038/s41598-017-03842-2] [Medline: 28634381] 
33. Wen K, Kreps G, Zhu F, Miller S. Consumers' perceptions about and use of the internet for personal health records and health information exchange: analysis of the 2007 Health Information National Trends Survey. J Med Internet Res 2010;12(4):e73 [FREE Full text] [doi: 10.2196/jmir.1668] [Medline: 21169163]

34. Hallberg I, Ranerup A, Kjellgren K. Supporting the self-management of hypertension: Patients' experiences of using a mobile phone-based system. J Hum Hypertens 2016 Feb;30(2):141-146 [FREE Full text] [doi: 10.1038/jhh.2015.37] [Medline: 25903164]

35. Health Information National Trends Survey. About HINTS. Bethesda, MD: National Cancer Institute URL: https://hints. cancer.gov/about-hints/learn-more-about-hints.aspx [WebCite Cache ID 72RV0fbjx]

36. Health Information National Trends Survey. Health Information National Survey 4 (HINTS 4) Cycle 2 Methodology Report. Bethesda, MD: National Cancer Institute; 2013 Mar. URL: https://hints.cancer.gov/docs/Instruments/

HINTS 4 Cycle2 Methods Report.pdf[WebCite Cache ID 72RUypHep]

37. Health Information National Trends Survey. Bethesda, MD: National Cancer Institute. Health Information National Survey 4 (HINTS 4) Cycle 4 Methodology URL: https://hints.cancer.gov/docs/Instruments/HINTS_4_Cycle2_Methods_Report. pdf $[$ WebCite Cache ID 72RUwXNxB]

38. Finney RLJ, Davis T, Beckjord EB, Blake K, Moser RP, Hesse BW. Picking up the pace: changes in method and frame for the health information national trends survey (2011-2014). J Health Commun 2012;17(8):979-989 [FREE Full text] [doi: 10.1080/10810730.2012.700998] [Medline: 23020763]

39. Czaja S, Sharit J, Nair S, Lee C, editors. Older adults internet health information seeking. In: Proceedings of the Human Factors Ergonomics Society Annual Meeting. 2009 Presented at: Human Factors Ergonomics Society Annual Meeting; 2009; San Antonio.

40. Hargittai E. Digital na(t)ives? Variation in internet skills and uses among members of the "net generation". Sociol Inq 2010;80(1):92-113. [doi: 10.1111/j.1475-682X.2009.00317.x]

41. Martinez VI, Marquard JL, Saver B, Garber L, Preusse P. Consumer Health Informatics Interventions Must Support User Workflows, Be Easy-To-Use, and Improve Cognition: Applying the SEIPS 2.0 Model to Evaluate Patients' and Clinicians' Experiences with the CONDUIT-HID Intervention. International Journal of Human-Computer Interaction 2017 Jan 11;33(4):333-343. [doi: 10.1080/10447318.2016.1278340]

42. Isaković M, Sedlar U, Volk M, Bešter J. Usability Pitfalls of Diabetes mHealth Apps for the Elderly. J Diabetes Res 2016;2016:1604609 [FREE Full text] [doi: 10.1155/2016/1604609] [Medline: 27034957]

43. Georgsson M, Staggers N. An evaluation of patients' experienced usability of a diabetes mHealth system using a multi-method approach. J Biomed Inform 2016 Feb;59:115-129 [FREE Full text] [doi: 10.1016/j.jbi.2015.11.008] [Medline: 26639894]

44. Mackert M, Mabry-Flynn A, Champlin S, Donovan EE, Pounders K. Health Literacy and Health Information Technology Adoption: The Potential for a New Digital Divide. J Med Internet Res 2016 Oct 04;18(10):e264 [FREE Full text] [doi: 10.2196/jmir.6349] [Medline: 27702738]

45. Mackert M, Champlin S, Holton A, Muñoz I, Damásio M. eHealth and Health Literacy: A Research Methodology Review. J Comput-Mediat Comm 2014 Apr 12;19(3):516-528. [doi: 10.1111/jcc4.12044] [Medline: 2014]

46. Protheroe J, Whittle R, Bartlam B, Estacio EV, Clark L, Kurth J. Health literacy, associated lifestyle and demographic factors in adult population of an English city: a cross-sectional survey. Health Expect 2017 Feb;20(1):112-119 [FREE Full text] [doi: 10.1111/hex.12440] [Medline: 26774107]

47. Amante DJ, Hogan TP, Pagoto SL, English TM, Lapane KL. Access to care and use of the Internet to search for health information: results from the US National Health Interview Survey. J Med Internet Res 2015;17(4):e106 [FREE Full text] [doi: 10.2196/jmir.4126] [Medline: 25925943]

48. Kontos E, Blake KD, Chou WS, Prestin A. Predictors of eHealth usage: insights on the digital divide from the Health Information National Trends Survey 2012. J Med Internet Res 2014;16(7):e172 [FREE Full text] [doi: 10.2196/jmir.3117] [Medline: 25048379]

49. Widmer R, Allison T, Keane B, Dallas A, Bailey K, Lerman L. Workplace Digital Health Is Associated with Improved Cardiovascular Risk Factors in a Frequency-Dependent Fashion: A Large Prospective Observational Cohort Study. PLoS ONE 2016;11(4):e0152657 [FREE Full text]

50. Kontos EZ, Viswanath K. Cancer-related direct-to-consumer advertising: a critical review. Nat Rev Cancer 2011 Feb;11(2):142-150. [doi: 10.1038/nrc2999] [Medline: 21258398]

51. Fox RC. Cultural competence and the culture of medicine. N Engl J Med 2005 Sep 29;353(13):1316-1319. [doi: 10.1056/NEJMp058066] [Medline: 16192475]

52. Beckjord EB, Finney RLJ, Squiers L, Arora NK, Volckmann L, Moser RP, et al. Use of the internet to communicate with health care providers in the United States: estimates from the 2003 and 2005 Health Information National Trends Surveys (HINTS). J Med Internet Res 2007 Jul;9(3):e20 [FREE Full text] [doi: 10.2196/jmir.9.3.e20] [Medline: 17627929]

53. Ramanadhan S, Viswanath K. Health and the information nonseeker: a profile. Health Commun 2006;20(2):131-139 [FREE Full text] [doi: 10.1207/s15327027hc2002 4] [Medline: 16965250]

54. Rutten LJF, Squiers L, Hesse B. Cancer-related information seeking: hints from the 2003 Health Information National Trends Survey (HINTS). J Health Commun 2006;11 Suppl 1:147-156. [doi: 10.1080/10810730600637574] [Medline: $\underline{16641080]}$ 


\author{
Abbreviations \\ CVD: Cardiovascular disease \\ eHealth: electronic health \\ HIE: health information exchange \\ HINTS: Health Information National Trends Survey \\ HIT: Health Information Technology \\ mHealth: mobile health \\ OR: odds ratio
}

Edited by G Eysenbach; submitted 16.11.17; peer-reviewed by H Shim, A Beatty, $R$ Widmer; comments to author 15.03.18; revised version received 19.04.18; accepted 10.05.18; published 18.10.18

Please cite as:

Asan O, Cooper II F, Nagavally S, Walker RJ, Williams JS, Ozieh MN, Egede LE

Preferences for Health Information Technologies Among US Adults: Analysis of the Health Information National Trends Survey

J Med Internet Res 2018;20(10):e277

URL: http://www.jmir.org/2018/10/e277/

doi: 10.2196/jmir.9436

PMID: 30341048

COnur Asan, Farion Cooper II, Sneha Nagavally, Rebekah J Walker, Joni S Williams, Mukoso N Ozieh, Leonard E Egede. Originally published in the Journal of Medical Internet Research (http://www.jmir.org), 18.10.2018. This is an open-access article distributed under the terms of the Creative Commons Attribution License (https://creativecommons.org/licenses/by/4.0/), which permits unrestricted use, distribution, and reproduction in any medium, provided the original work, first published in the Journal of Medical Internet Research, is properly cited. The complete bibliographic information, a link to the original publication on http://www.jmir.org/, as well as this copyright and license information must be included. 